\title{
VIOLÊNCIA E BULLYING NA ESCOLA
}

\author{
Diego Tavares do Nascimento 1
}

RESUMO: A violência e o bullying nas escolas são principalmente cometidos por colegas, mas, em alguns casos, por professores e outros funcionários da escola. A justificativa e relevância para este estudo está na necessidade de compreender que a abordagem da violência escolar e do bullying é essencial para alcançar os Objetivos de Desenvolvimento Sustentável (ODS) de um país. Quais são a consequências da violência no meio educacional? O objetivo geral deste estudo é apresentar as possíveis causas e soluções da violência escolar. A violência escolar e o bullying podem ser devastadores para as vítimas. As consequências incluem crianças e jovens que têm dificuldade em se concentrar nas aulas, faltam às aulas, evitam atividades escolares ou abandonam a escola completamente. Este estudo é uma revisão bibliográfica. Apesar das suas diferenças, existem fortes ligações entre bullying e violência. Ambos os agressores e suas vítimas são mais propensos a se envolverem em outros comportamentos violentos.

Palavras-chaves: Bullying. Violência. Escola. Prevenção.

\section{INTRODUÇÃO}

A violência e o bullying nas escolas são principalmente cometidos por colegas, mas, em alguns casos, por professores e outros funcionários da escola. $\mathrm{O}$ monitoramento do progresso em direção ao objetivo de fornecer um ambiente de aprendizado seguro, sem violência, inclusivo e eficaz exige dados precisos e atualizados, que incluem dados de tendências.

A justificativa e relevância para este estudo está na necessidade de compreender que a abordagem da violência escolar e do bullying é essencial para alcançar os Objetivos de Desenvolvimento Sustentável (ODS) de um país, que visa garantir uma educação de qualidade inclusiva e equitativa e promover oportunidades de aprendizagem ao longo da vida para todos, que visa promover a paz e as sociedades inclusivas.

De acordo com o ilustrado acima, surge uma questão de pesquisa para ser compreendida: Quais são a consequências da violência no meio educacional? A violência relacionada à escola, em todas as suas formas, é uma violação dos direitos das crianças e

\footnotetext{
${ }^{1}$ IEGRS- Ensino Médio - Formação de professores . SENAC: Curso técnico em Secretaria Escolar. UERJLicenciatura Plena em Pedagogia FAPI-Pós - Graduação em Gestão Educacional. UDE (Uruguai)-Mestrando em Educação: 3ํㅜㄹeríodo. E-mail: pedagogodiego@gmail.com.
} 
adolescentes à educação e à saúde e bem-estar. Nenhum país pode obter educação inclusiva e equitativa de qualidade para todos, se os alunos sofrerem violência e bullying na escola.

O objetivo geral deste estudo é apresentar as possíveis causas e soluções da violência escolar. E tem como objetivos específicos: Descrever conceitos e contexto relacionados a violência e ao bullying no ambiente escolar; identificar o comportamento do bullying; apontar os alvos do bullying; compreender o comportamento e a mediação diante da situação; apresentar sugestões e práticas contra o bullying; apresentar a possível reabilitação dos valentões; identificar o ambiente escolar de ocorrências do bullying; e apresentar possíveis conclusões básicas sobre a violência nas escolas.

Hipoteticamente, a violência escolar e o bullying podem ser devastadores para as vítimas. As consequências incluem crianças e jovens que têm dificuldade em se concentrar nas aulas, faltam às aulas, evitam atividades escolares ou abandonam a escola completamente.

Este estudo é uma revisão bibliográfica. Pesquisas desse tipo tem o objetivo primordial à exposição dos atributos de determinado fenômeno ou afirmação de relações entre as variáveis (GIL, 2008). Assim, recomenda-se que apresente características do tipo: analisar a atmosfera como fonte direta dos dados e o pesquisador como um instrumento interruptor; não agenciar o uso de artifícios e métodos estatísticos; tendo como apreensão maior a interpretação de fenômenos e a imputação de resultados; o método deve ser o foco principal para a abordagem e não o resultado ou o fruto; a apreciação dos dados deve ser atingida de forma intuitiva e indutivamente através do pesquisador (GIL, 2008).

Várias bibliografias de autores com expressão significativa em campo científico foram pesquisadas. O levantamento dos dados e das informações relevantes para à investigação e o entendimento das questões propostas, utilizadas técnicas de bibliografia indireta (GIL, 2008). Também foram pesquisadas e coletadas informações relevantes na internet acerca do tema, delineando a reflexão conforme se veem, bem como as referências bibliográficas citadas neste estudo.

\section{DESENVOLVIMENTO}

Através de dados de pesquisas mundiais, sabe-se que as crianças são altamente suscetíveis a violência que a mídia promove, domina, ou cria novos caminhos para a 
existência do bullying (ANDERSON e BUSHMAN, 2002). A mídia violenta oferece uma estrutura social e um modelo para o intrépido seguir (CARVALHO, 1998). Crianças que talvez não considerem usar violência para intimidar outros podem fazê-lo quando estiverem expostos à mídia, que retratam comportamentos de bullying sendo recompensados.

Tais recompensas são facilmente evidentes em mídias tão recentes como o lançamento do vídeo game de Rockstar em 2006 "Bully" (Valentão), em que o bullying é glorificado e encorajado. Como esses jogos se tornam cada vez mais populares e os números de potenciais agressores aumentam. Desta forma, bullying e violência estão inextricavelmente ligados, à medida que os agressores se alimentam da mídia que retrata violência contra os outros.

A indústria responde com uma produção escalonada deste tipo de informação, além de interagir com meios violentos, muitas crianças observam ou experimentam este tipo de comportamento. Observando tais comportamentos, especialmente se não veem consequências de punição aos que praticam, promovem a probabilidade de outros imitarem (BANDURA, 1986). Os que praticam são quatro vezes mais propensos a se tornarem criminosos do que os que não, no futuro serão condenados por crimes graves antes dos 24 anos (OLWEUS, 1993).

O termo "bullying" foi usado pela primeira vez em 1958. Bullying é um comportamento preparativo específico de animais selvagens em defesa a ataques de outros animais. $\mathrm{Na}$ década de oitenta, um médico sueco e psicólogo Heinz Leyman, o primeiro a usar este termo em relação à sociedade, descreveu não ser incomum na Suécia e no mundo casos de maus tratos de indivíduos ou grupos entre si. Atualmente, o termo continua sendo usado, persistente e repetitivo, sendo assédio moral e intimidação por indivíduos a uma pessoa ou grupo de pessoas, a fim de obter humilhação, ridicularização, isolamento, ou mesmo uma eliminação. Embora a palavra tenha uma estranha sonoridade e usado em nossa língua por apenas alguns anos, o fenômeno já é conhecido há muito tempo (NCUBE, 2013).

No início foram identificados, em locais de trabalho e relacionamentos entre empregador e empregados ou entre os funcionários. No presente, este fenômeno também ocorre em escolas, o ambiente dos estudantes. Sem dúvida, para os alunos da escola, é um lugar onde a maioria pode se tornar uma vítima ou autor. O bullying e a violência escolar são 
muitas vezes resultados das diferenças de aparência, comportamento ou status social de um jovem, em que outras quando praticam, alcançam prazer (NCUBE, 2013).

\section{I COMPORTAMENTO DO BULLYING}

A maioria dos programas de intimidação a violência identificam três grandes formas de assédio moral, físicos, emocionais e verbais. O bullying físico inclui o contato, causando desconforto para outro indivíduo. O bullying emocional é uma forma de agressão sem palavras, como na exclusão e ignorando comportamentos. O verbal é conhecido como bullying aconselhamento ou agressão relacional (ESPELAGE e SWEARER, 2003), pode ser visto quando uma menina relata que outra garota não está falando com ela e a encoraja para que todos os outros façam o mesmo. Uma combinação de emoções e o bullying verbal podem ser agrupados vagamente, não seguindo categorias comuns, a palavra Bully, quer dizer valentão ou tirano, será usado o termo "valentão" no decorrer do estudo (Spelage e Swearer, 2003):

(I) Valentão Mentiroso: Uma criança exibindo este gênero de bullying pode produzir uma convincente conduta a qualquer momento quando esconde seus atos violentos. Tais valentões se transformam em decepção, e sua capacidade de enganar nunca deve ser subestimada.

(2) Valentão dissimulado: Esse valentão é cruel e vingativo em particular, mas é inocente e útil na frente de testemunhas. Um atributo em comum e um sinal de aviso deve ser observado quando ele se exibe com charme excessivo na frente daqueles que são considerados autoridades.

(3) Valentão superficial: Tem excepcional capacidade verbal, mas nenhuma substância para apoiar seus argumentos muitas vezes ilógicos, que são projetados para magoar os outros. Este valentão geralmente fala de um "grande jogo", mas não assume compromissos e não pode ser confiável ou invocado. $O$ valentão superficial tende a criar conflito para minar e destruir qualquer um que ele perceba ser um adversário ou uma ameaça em potencial capaz de desmascará-lo.

(4) Valentão crítico: Este tipo de bullying frequentemente usa táticas secretas para humilhar, constranger, degradar ou diminuir os outros. Tais valentões dependem de 
mimetismo, insultando, provocando, constrangedor em interrogatório e recusas a valorizar outros.

(5) Valentão pressão: Usam seus poderes persuasivos repetidamente para convencer os outros a aceitar suas opiniões e percepções. Esses agressores empregam boatos e insinuações com grande habilidade para destruir a reputação dos outros. Eles exibem arrogância, juntamente com um senso superior de direito e audácia, enquanto acreditando que são invulneráveis e intocáveis.

(6) Valentão evasivo: Esses agressores raramente dão uma resposta direta à conversação, tópico para evitar a responsabilidade por suas transgressões contra os outros. Eles são rápidos para desacreditar outros e neutralizar qualquer um que tenha informações incriminadoras sobre eles.

Além disso, valentões tem frequentemente complexas e contraditórias tendências psicológicas que contribuem para os altos níveis de dor emocional, que pode assumir muitas formas. Alguns provocadores por exemplo, tem persistentes sentimentos de inferioridade, inadequação e insegurança, o que resulta em auto aversão. Essas crianças ou jovens muitas vezes optam por se tornar valentões para mitigar seus sentimentos de frustração e fracasso (UNESCO, 2017).

Os outros parecem ter autoestima elevada e usam comportamentos de bullying para solidificar seus sentimentos de autoestima. Estatura do emocional tipicamente imatura do valentão muitas vezes resulta em uma incapacidade de sentir empatia com os outros (ESPELAGE e PRAGUEJADOR, 2003). Manifesta-se muitas vezes a impaciência e raiva quando colocados em situações que exigem empatia. $O$ valentão pode ver qualquer tentativa de ser empático como vulneráveis e, por conseguinte, um alvo em potencial.

Tal fraqueza percebida pode excitá-lo em iniciar etapas para publicamente ignorar ou substituir empáticas manifestações do indivíduo, em um esforço para testar a adequação do alvo potencial para ainda mais bullying. Este tipo de alvo é referido como uma vítima provocativa (SMITH, 2018). Um alvo que se opõe a esses passos iniciais pode intimidar o valentão de mais avanços. Como parte deste processo, valentões raramente se desculpam ou dão elogios aos outros; em vez disso, eles são muitas vezes sarcásticos e podem ter uma necessidade natural de serem reconhecidos. 
Os métodos que valentões empregam quando eles interagem com outros muitas vezes resultam em depressão e solidão, que só aumenta sua dor emocional. Finalmente, valentões, muitas vezes são consumidos pelo medo e ciúme. Muitas vezes temem enfrentarse, perdendo seguidores e perdendo poder sobre os outros. Eles podem ter ciúmes dos outros, porque seu sistema de crenças pessoais sugere que estão sendo enganados regularmente em todos os aspectos da sua vida. Noções básicas sobre os tipos de intimidações e seus atributos psicológicos típicos, são mais fáceis para efetuar mudanças positivas nestes indivíduos (SMITH, 2018).

\subsection{MUDANDO O COMPORTAMENTO}

Quando um jovem se envolve em comportamento de bullying pode-se ajudá-lo a aprender maneiras mais positivas de se relacionar com as pessoas. A maioria das pessoas que tiranizam não são "más", mas elas precisam aprender a se relacionar positivamente com os outros. Intimidar os outros e serem autorizados a continuar está associado a riscos na escola, nas relações pessoais e no trabalho. Também aumenta a probabilidade de condenações penais. Quando jovens intimidam, precisamos levar a sério e requer pais e professores que trabalhem juntos para ajudá-los a mudar seu comportamento. Não se trata de culpar ninguém, é sobre ajudar o jovem a desenvolver comportamentos mais positivos. São processos eficazes (Rodkin e Hodges, 2013):

(I) Encontro com o professor do seu filho para discutir o assunto;

(2) Selecionar um comportamento negativo para substituir e um comportamento positivo alternativo para incentivar e recompensar. É melhor começar com um comportamento que se sente mais fácil mudar primeiro;

(3) Avaliar o comportamento de o a ı, io se ocorre o tempo todo, zero se nunca ocorre;

(4) Elaborar uma estratégia para recompensar o comportamento positivo e uma estratégia para ser mais pró ativamente vigilante sobre o comportamento negativo;

(5) Concordar em permanecer em contato com a escola, como quando questões surgem; 
(6) Perceber o comportamento temporariamente que pode piorar antes que melhore. Ser gentil, calmo e firme;

(7) Aceitar sair formalmente em cerca de 5 a 6 semanas para rever o progresso;

(8) Se o progresso tem sido alcançado, celebrar e selecionar o seguinte comportamento para alterar se necessário; e

(9) Se o comportamento do problema não mudou precisa repensar estratégias ou buscar apoio profissional.

Uma vez que o comportamento mudou, outras mudanças, aparentemente mais difíceis, deve-se buscar a mudança através desses processos também. A razão para isto é que muito do comportamento é modelado em hábitos. Mudança de um elemento de um hábito pode começar a mudar toda sequência de comportamento. Portanto, pode precisar repetir este processo várias vezes (SMITH, 2018).

Quando valentões não seguem essas regras, a maioria dos programas sugere que infrações sejam abordadas em particular, uma vez que priva os valentões do público que muitas vezes o procuram. Na abordagem em adultos, em particular, com confiança, sem hesitação e consistentemente deve empregar as consequências adequadas bem estabelecidas para os comportamentos de bullying (UNESCO, 2017).

O valentão precisa ser aconselhado separadamente, tanto durante como após o incidente. Além disso, precisa ser acompanhado com as melhores escolhas para o comportamento e instruído sobre como melhorar suas interações sociais. Também precisa ser corrigido com concretas palavras e ações como substitutos para o comportamento de bullying (UNESCO, 2017).

Por exemplo, se uma criança exclui outra criança de brincar com um grupo no recreio, a criança precisa entender que esse comportamento não será tolerado e que é uma regra que todas as crianças devem ser incluídas. Instrução explícita deve ser dada sobre como permitir que todos podem jogar e como ativamente procurar indivíduos tímidos e pedir-lhes para se juntar ao grupo. Ao longo do tempo, esta mudança positiva no comportamento pode tornarse mais gratificante aos fanfarrões que seu comportamento anterior (SMITH, 2018). 


\subsection{OS ALVOS DO BULLYING}

Programas de intimidação frequentemente sugerem que as crianças devem ter oportunidades cotidianas para se envolver em discussões com seus professores sobre suas relações sociais na escola. Usando as ideias que eles recolhem a partir dessas discussões, os professores devem oferecer orientações específicas relativas ao assédio moral e violência. Deve ser claro que o assédio moral pode ser identificado, observando as ações de intimidação em relação aos outros e notar a ausência de tais comportamentos como se desculpando, ajudando ou elogiando os outros (NCUBE, 2013).

Muitas vezes, crianças descrevem os pares que se comportam desta maneira como "média", e professores devem esclarecer que estes comportamentos são uma indicação de que o indivíduo pode ser um valentão. Assédio moral deve ser descrito como aqueles indivíduos que não sabem como tratar ou lidar com sentimentos de depressão, inferioridade, inadequação, insegurança, medo ou inveja. Adultos devem orientar as crianças para entender que alvos de bullying, mais do que provavelmente, não fez nada para incentivar tal comportamento negativo (NCUBE, 2013).

Em vez disso, são muitas vezes eles que exibem a bondade e compaixão para com os outros. Reconhecendo tal bondade, valentões muitas vezes são forçados a enfrentar a sua própria incapacidade de comportar-se de tal maneira e então chicotear para fora. Alvos de bullying são muitas vezes elogiados pela sua bondade. Este reconhecimento é provável que enfureça os indivíduos que se sentem inclinados a intimidar, aumentando, ainda mais, seus sentimentos de inferioridade e insegurança. Alvos de bullying devem ser ajudados a perceber que eles provavelmente não são o primeiro alvo do valentão e que eles provavelmente foram alvo porque o valentão sentiu algum tipo de vulnerabilidade. Valentões podem procurar desafiar a integridade do alvo e relutam em se comprometer com algo positivo e bem definido de valores (MATTOS e SILVA, 1983).

\subsection{COMPORTAMENTO E MEDIAÇÃO}

Enquanto a presença de professores e de gráficos de comportamento pode ajudar a limitar o assédio moral dentro da sala de aula, ajuda adicional é necessária para abordar assédio moral fora da sala de aula. Uma maneira de abordar esta questão é discutir as responsabilidades dos espectadores em lidar com valentões. Levantando-se para esse destino 
não é uma tarefa fácil. Espectadores podem ter medo de enfrentar o valentão com medo de reativá-los (MANSEL, 20oI).

Professores devem explicar que eles provavelmente serão orientados pelo valentão a não intervir em nome de um destino atual. Muitas vezes, a única forma de virar alguns provocadores habituais é através do confronto direto. As crianças precisam entender que todos são responsáveis pela eliminação de intimidação e violência. Adultos devem garantir as crianças que valentões geralmente vão parar com o assédio moral, quando duas ou mais pessoas o enfrentarem e que terão consequências adequadas aplicadas (MANSEL, 200I).

Após ser rejeitado por um grupo, valentões, muitas vezes afirmam que eles são vítimas. No entanto, as crianças devem ser encorajadas a não deixar essa reação influenciar sua insistência de que os comportamentos de bullying devem cessar. As crianças precisam de maior força e coragem para rejeitar um valentão. Os adultos devem ensiná-las que nunca se arrependerão ao fazê-lo, e que receberão ajuda. Esta ajuda pode vir na forma de exercícios destinados a rejeição assertivamente ao assédio moral. Devem ser advertidas de usar palavras fortes apenas quando eles estão realmente sendo intimidados e se eles acreditam que tais táticas não irão agravar a situação (MEIER e TILLMANN, 2oıo).

As crianças menores podem não entender completamente o momento apropriado para usar estas frases ou agir quando eles sentem que eles estão sendo intimidados. Aprender a defender-se de assédio moral é um contínuo processo. Um professor de orientação e compreensão durante esse processo é fundamental. Além disso, se as crianças sentem que estão em perigo, seu primeiro recurso deve ser para procurar a ajuda de um adulto (MEIER e TILLMANN, 2010).

\subsection{SUGESTÕES PRÁTICAS CONTRA O BULLYING}

Muitos programas de intimidação encorajam as crianças a falar contra ou rejeitar os valentões. No entanto, um indivíduo que tem sido intimidado por um período de tempo pode ser mais difícil dissuadir o comportamento do valentão. Felizmente, algumas respostas, capacitam o alvo, não importa quanto tempo ele ou ela tem sido intimidado. Ainda, o alvo nesta situação vai precisar de mais apoio e incentivo dos professores e adultos em sua vida para ser bem-sucedido em parar o ciclo de intimidação. Altos e baixos são prováveis de 
ocorrer antes que o bullying cesse, o valentão e o alvo tendem a cair facilmente nos seus papéis anteriores (LEFF et al., 2003).

O alvo deve ser fornecido com explícitas palavras e ações para reverter o bullying. Ao valentão, deve ser fornecido sugestões de comportamentos alternativos. Assim, o mais profundo e arraigado ciclo tirano pode ser interrompido. Muitos programas de intimidação incentivam metas a usar "Mensagens", como elas podem ser muito eficazes em dissuadir um valentão (tais como, "não gosto o que estão fazendo e quero que pare de"). O que fazer (Leff et al., 2003):

(I) Ignorar o comportamento do valentão, sempre que possível;

(2) Usar as habilidades sociais, tais como ser assertivo, negociar, compartilhar, revezando, convidando os outros a participar, ajudar outras pessoas e pedindo permissão;

(3) Deixar a situação;

(4) Rejeição de forma firme;

(5) Proteja-se emocionalmente e fisicamente (sem o uso de retaliação). Solicitar que o valentão pare e em seguida bata o pé;

(6) Usar o humor;

(7) Fingir concordar com o valentão (isto pode leva-lo para longe);

(8) Gastar tempo em grupos; e

(9) Praticar o que dizer na frente de um espelho ou com amigos.

O que não fazer:

(I) Chorar ou sentir-se ferido na frente do valentão;

(2) Perder o seu temperamento;

(3) Agravar a situação;

(4) Responder com agressão;

(5) Chamar outros para conspirar contra o valentão;

(6) Maquinar retaliação;

(7) Responder com xingamentos; e 
(8) Trazer armas para a escola.

\subsection{REABILITAÇÃO DE VALENTÕES}

Alguns sugerem que os valentões nunca devem ser dados uma segunda oportunidade ou ser perdoado, enquanto outros suportam perdoando os comportamentos de bullying (LIMBER e SMALL, 2003). Para as crianças que lidam primeiro com o valentão e são imediatamente rejeitadas, pode haver grande valor em perdão dos pares. Esse perdão pode levar o valentão permanentemente abandonar comportamentos de bullying, porque o valentão pode ganhar mais como uma forma diferente de agir, menos individual.

Sociedades não devem subestimar a capacidade infantil de compreender as motivações do valentão e o papel que podem desempenhar para ajudar a construir a psique potencialmente frágil de um, uma vez que o valentão pode abandonar formas de intimidação. Quando o valentão abandonar o comportamento bullying, vai continuar a precisar de ajuda para compreender os aspectos de sua personalidade que levaria aos atos (LIMBER e SMALL, 2003).

Além disso, valentões devem ser continuamente apoiados com comportamentos alternativos explícitos, positivos e direções para interações verbais e físicas com os seus pares. Valentões devem ser lembrados continuamente que será melhor ser amado por outros, gostar-se mais, e que receberá recompensas maiores ao ajudar os outros (LEYMANN, 1997).

Rodkin e Hodges (2003) encontraram que os professores que mostram carinho e bondade para todas as crianças em uma classe fazem um impacto na redução do bullying, fornecendo um modelo positivo. Kilpatrick-Demaray e KerresMalecki (2003) sugerem a atribuição de amigos para todos os alunos como uma etapa preventiva para reduzir o bullying na sala de aula.

\subsection{O AMBIENTE ESCOLAR}

Estudos sobre a influência do ambiente escolar e sistemas educacionais sobre o desenvolvimento acadêmico dos jovens já foram realizados, mas também devem ser abordadas do ponto de vista dos cuidados de saúde. A escola tem um significado importante para as crianças e adolescentes. Aqueles que não gostam deles são mais propensos a mostrar 
o desempenho insatisfatório, problemas físicos e emocionais ou sentimentos insatisfeitos com a vida (MEIER e TILLMANN, 20I0).

Relações interpessoais positivas e desenvolvimento acadêmico estão diretamente interligados, estudantes realizando essa relação são mais propensos a alcançar um bom nível de aprendizagem. Portanto, aceitação de mesmo nível, é fundamental para o desenvolvimento da saúde de crianças e adolescentes, ajuda a refinar suas habilidades sociais e fortalecer a capacidade de reagir contra situações tensas (MANSEL, 200I).

Agressividade em escolas é um problema universal. Bullying e a vitimização representam diferentes tipos de envolvimento em situações de violência durante a infância e adolescência. Bullying é uma forma de poder interpessoal, afirmação através de agressão. Por vitimização significou o comportamento agressivo para com uma pessoa menos poderosa de uma pessoa mais poderosa. Bullying e vitimização podem ter repercussões imediatas e de longo prazo. Resultados em todos os indivíduos envolvidos: agressores, vítimas e observadores. Bullying compreende todos os tipos de agressão intencional e repetida sem causa óbvia por um ou mais estudantes contra outro (s), causando dor e angústia, isso acontece nas relações de poder desiguais (MANSEL, 200I).

A assimetria pode resultar de diferenças de idade, tamanho, desenvolvimento físico ou emocional ou o agressor encontrar apoio da maioria dos estudantes. O termo bullying é universalmente aceito, mas é difícil traduzir para outras línguas. A pesquisa sobre bullying é bastante recente e ganhou espaço nos anos de 2012 pra cá, especialmente com as obras de Olweus (1993). Estudos indicam uma prevalência de 84,6\% para crianças ameaçadas e 53\% para infratores ativos regulares (UNESCO, 2017).

Tradicionalmente, a escola é vista como um lugar para aprender onde o desempenho dos alunos é avaliado com base em testes, notas e realização de tarefas acadêmicas. Três documentos legais formam a base para a compreensão das crianças, o desenvolvimento e a educação dos adolescentes: a Constituição Brasileira, o Estatuto da Criança e Adolescentes e a Convenção das Nações Unidas sobre os direitos da criança. Estes documentos são sobre como crianças e adolescentes devem ser respeitados e tratados com dignidade. Educação é entendida como um meio para fornecer aos indivíduos desenvolvimento completo e preparálos para a prática da cidadania. 
Todos queremos que a escola seja um lugar seguro e saudável, onde crianças e adolescentes podem desenvolver suas habilidades intelectuais e sociais ao ponto máximo. No entanto, não é admissível para eles submeter-se ao comportamento violento que os causa lesões físicas e psicológicas (UNESCO, 2017).

A Associação Brasileira de Multiprofissional para a Proteção das Crianças e Adolescentes (ABRAPIA), que encerrou suas atividades em 2008, desenvolveu o programa de redução do comportamento agressivo entre estudantes, com o objetivo de investigar as características dos acontecimentos violentos entre 5.500 escolas de alunos do ensino fundamental e conceituar estratégias de intervenção que poderiam evitar o assédio moral. Embora o programa durou um pouco mais de um ano, entre setembro de 2002 a outubro de 2003, foi possível reduzir o comportamento agressivo entre estudantes, aumentando o ambiente escolar, aprendizagem de nível, conservação de propriedade e, mais importante, as relações humanas (QUADRO i e 2).

QUADRO I - Percepção dos alunos sobre a prática de bullying nas escolas

- $40,5 \%$ dos alunos admitiram que estavam diretamente envolvidos em atos de bullying, destes, $16,9 \%$ estavam envolvidos como metas, $12,7 \%$ como autores e 10,9\% como alvos e autores;

- $60,2 \%$ dos alunos disseram que o bullying foi mais frequente dentro da sala de aula;

- $80 \%$ dos alunos tiveram sentimentos negativos em relação ao bullying, como medo, piedade, tristeza, etc.

- $41,6 \%$ daqueles que admitiram serem alvo de bullying disseram que não buscaram ajuda de colegas, professores ou família;

- Entre aqueles que pediram ajuda para reduzir ou acalmar sua angústia, apenas $23,7 \%$ alcançaram seu objetivo;

- $69,3 \%$ dos alunos disseram que não conheciam os motivos pelos quais o bullying acontece ou que eles acreditam que é um tipo de piada;

- entre intimidantes, $51,8 \%$ disseram que não estavam orientados nem advertidos sobre a gravidade de seus atos.

Fonte: ABRAPIA - Dados obtidos na pesquisa inicial realizada pela ABRAPIA 
QUADRO 2 - Percepção do aluno sobre a prática de bullying dentro das escolas

- $79,9 \%$ disseram que sabem o que é bullying;

- redução de $6,6 \%$ dos alunos-alvo;

- redução de $12,3 \%$ dos valentões;

- a indicação da sala de aula como o lugar com maior incidência de atos de bullying sentiu de 60,2 a $39,3 \%$, representando uma redução de $24,7 \%$;

- o número de estudantes que admitiram ter gostado de ver os outros serem intimidados diminuiu $46,1 \%$;

- entre os estudantes-alvo que procuraram ajuda, o sucesso das intervenções para a redução ou cessação do bullying aumentou 75,9\%;

- a falta de conhecimento sobre a compreensão de razões que levaram a prática de bullying reduziu $49,1 \%$;

- respostas que admitem bullying como um ato maligno aumentou de $4,4 \%$ para $25,2 \%$, o que representa um aumento de $472,7 \%$;

- o número de intimidantes admitiu que eles estavam orientados e advertidos sobre a gravidade de seus atos.

Fonte: ABRAPIA - ALTERAÇÕES DETECTADAS NA AVALIAÇÃO FINAL DO PROJETO

\subsection{CONCLUSÕES BÁSICAS SOBRE A VIOLÊNCIA NAS ESCOLAS}

Mesmo que várias empresas científicas discursem sobre este tema, fazer uso de terminologia semelhante, que deve ser salientado, que a violência nas escolas é um fenômeno heterogêneo. Os tópicos de pesquisa abrangem uma vasta gama de comportamentos que variam de ataques físicos intencionais, incluindo o uso de armas, violência de gangues e agressões sexuais para comportamentos menos graves como batendo e batendo, para socos e chutes relativamente inofensivos. Até agora, não há nenhuma classificação internacional por tipo de comportamentos violentos - principalmente porque a prevalência relativa de vários tipos de violência nas escolas difere entre países e continentes (UNESCO, 2017) .

No entanto, a definição de Olweus (1993) poderá servir como um padrão preliminar: violência é "comportamento agressivo onde o ator ou autor usa seu próprio corpo ou um objeto (incluindo uma arma) para infligir ferimentos (relativamente graves) ou desconforto sobre outro indivíduo" (OLWEUS, 1993, p.12). No entanto, essa definição deixa um monte de tópicos específicos quanto às respectivas definições: a maioria dos estudos enfocam violência realizada dentro dos limites da escola; no entanto, outros incluem comportamentos 
violentos por estudantes no caminho para a escola ou em outros lugares fora das escolas (GARCIA e TOLFO, 20II).

$\mathrm{Na}$ literatura existente, encontramos análises sobre comportamentos fortemente violentos como o usando facas e armas e a violência de gangues, no entanto, há também muita atenção para a violência de nível inferior como chutar ou bater (FUCHS et al., 1996, 200I, 2008). Além de violência física contra outros estudantes, vários tipos de danos à propriedade e vandalismo na escola, bem como a agressão verbal e outros tipos de não-físicos de agressão são incluídos nos respectivos estudos, como o assédio moral, coerção e intimidação (OLWEUS, 1999).

O foco da literatura existente é predominantemente em formas mais leves de comportamentos justiçáveis, bem como em comportamentos abaixo do limite da lei penal. A literatura disponível documenta uma ampla gama de resultados consistentes sobre a prevalência da violência nas escolas da Europa (SMITH, 2013). De um modo geral a prevalência de comportamentos violentos é bastante baixa, pelo menos mais baixo do que o esperado, baseia-se atenção considerável neste tópico. Além disso, achados não sugerem nenhum aumento sustentável da violência nos últimos io anos, que também está em contraste com a percepção do público em geral.

Violência física severa é rara e formas mais leves de violência são uma passagem na transição da infância para adultos apenas para uma pequena proporção, violência desenvolve-se em um padrão diário de conflito resolvendo comportamento (ECKERT, 2010). Diversos estudos indicam que o impacto das características individuais do autor sobre a prevalência da violência nas escolas. $\mathrm{Na}$ verdade, a maioria das pesquisas assumiram uma posição bastante etiológico desde que incidem sobre as características individuais como chave das causas de violência nas escolas. A seguir, uma lista de fontes selecionadas que têm sido associadas com a ocorrência do comportamento violento (Leff et al., 2003):

(I) Quase todos os estudos tem apontado, que alunos do sexo masculino são mais violentos em comparação com estudantes do sexo feminino. Isto é especialmente verdadeiro para violência física; no caso de agressão verbal, a diferença é menor, no entanto, ainda é visível; 
(2) Violência parental foi identificada para estimular a violência na escola. Esta correlação tem sido demonstrada para padrões agressivos entre os pais ou - ainda mais pronunciado - para a violência dos pais contra seus filhos;

(3) As crianças de famílias em condições socioeconômicas desfavorecidas severamente têm provadas serem mais violentas do que crianças de famílias mais ricas. Isto é especialmente verdadeiro para os pais que estão desempregados ou para atrair apoio de assistência social locais. No entanto, dada a literatura à mão não está claro se este efeito resulta diretamente do sócio desvantagem econômica ou se a privação relativa em comparação com os colegas de classe superior estimula comportamentos violentos por estas crianças;

(4) Vários dos estudantes altamente violentos são membros de grupos iguais. Isto levantou a pergunta até que ponto a interação com a gangue pode estimular comportamentos violentos na escola. No entanto, deve notar-se que a direção causal ainda não está confirmada - também pode ser que escolheu estudantes violentos para entrar em um grupo violento porque eles próprios são propensos a comportamentos agressivos; e

(5) A mesma falta de clareza se aplica a muitas vezes assumida a influência do consumo de mídia violenta e PC games ou jogos online. No entanto, dada os projetos de pesquisa na mão é difícil de provar que o consumo de conteúdo de mídia violenta na verdade evoca individual comportamento violento. Bem pode ser que o aluno que é violento por causa de outros motivos é especialmente interessado em jogos para PC violentos ou agressivo de jogos online porque eles são violentos. A violência é um problema de saúde pública crescente em todo o mundo, causando sérios danos individuais, especialmente aos jovens, que de acordo com as estatísticas são os mais gravemente feridos, e quem mais comete homicídios. Atualmente, um consenso onde a violência pode ser prevenida, o seu impacto minimizado e fatores que contribuem para alteraram respostas violentas.

De acordo com Debarbieux e Blaya (2014), isto não é uma ilusão, mas uma afirmação baseada em evidências. Existem muitos exemplos bem-sucedidos de diferentes partes do mundo, do trabalho individual e em pequena escala da Comunidade, para as políticas 
nacionais e iniciativas jurídicas. Uma das formas mais visíveis da violência é violência juvenil, chamada para ser perpetrados por jovens entre io e 21 anos de idade. Grupos em que um violento comportamento é detectado antes da puberdade tende a apresentar comportamento agressivo que aumenta com a idade e o pico com atitudes prejudiciais durante a adolescência, persistindo até a idade adulta.

Como para o ambiente no qual a violência contra crianças e adolescentes ocorrem, a escola aparece como um espaço que não tem ainda sido totalmente explorado, especialmente no que se refere a comportamento agressivo entre estudantes. Violência na escola é grave e complexo. Problema social e provavelmente o problema mais frequente e visível da violência juvenil. A escola do termo violência compreende todos os tipos agressivo e antissocial. Comportamento, incluindo os conflitos interpessoais, danos à propriedade, atos criminosos, etc. (DEBARBIEUX e BLAYA, 2014)

\section{CONCLUSÃO}

Apesar das suas diferenças, existem fortes ligações entre bullying e violência. Ambos os agressores e suas vítimas são mais propensos a se envolverem em outros comportamentos violentos. As vítimas geralmente sofrem de depressão e baixa autoestima e podem responder a ataques violentamente, enquanto os agressores são mais propensos do que outros a praticar comportamentos criminosos violentos. Tanto a violência quanto o bullying podem fazer com que os alunos tenham medo e deixem a escola.

Assédio moral não deve ser considerado uma fase "normal" de desenvolvimento da criança. Em vez disso, ele deve ser visto como um precursor para comportamentos violentos mais graves que exigem intervenção imediata e apropriada por um adulto cuidador. Se quisermos que as sociedades locais deem segurança para todos, as escolas precisam fornecer liderança instituindo programas de intimidação que incluem a intervenção precoce, formação de adultos e as intervenções de intimidação de toda a escola para os alunos (FURLONG, MORRISON, e GREIF, 2003). Nossas crianças e nosso mundo merecem esse cuidado. 


\section{REFERÊNCIAS}

ABRAPIA, Fundação. Associação Brasileira Multiprofissional de Proteção à Infância e à Adolescência. Disponível em:

〈http://ses.sp.bvs.br/lis/resource/446\#.WX5ztRXyuUk>. Acesso em: 20 jan. 2020.

ANDERSON, C. A., e BUSHMAN, B. J. Agressão humana. Annual Review of Psychology, 53, p.27-51. 2002.

BANDURA A. Fundamentos sociais do pensamento e da ação: uma teoria cognitiva social. nglewood Cliffs, NJ: Prentice Hall. 1986.

CARVALHO, E. R. de. Edição crítica de Marco Zero I: a revolução melancólica. São Paulo: FFLCH-USP. (Dissertação de mestrado). 1998.

DEBARBIEUX, E., BLAYA, C. Violence in Schools. Ten Approaches in Europe. Issy-lesMoulineaux: ESF Editeur. 20I4.

ECHERT, R. Violência juvenil na Alemanha, em FOLJANTY-JOST, G., Ed., Schule, Schüler und Gewalt, München: Iudcium, p.13-30, 2010.

ESPELAGE, D. L., e SWEARER, S. M. Pesquisa sobre bullying escolar e vitimização: O que aprendemos e para onde vamos daqui? Revisão de Psicologia Escolar, 32(3), p.365-383. 2003.

FUCHS, M., Propriedade de armas entre crianças e adolescentes na ALEMANHA, H. v., Ed., ebenschancen und Lebensrisiken in der neuen Bundesrepublik. Opladen: Leske + Budrich, p.103-120. 1995a. 
FUCHS, M., LUEDTKE, J., Eds., Desvio e outros problemas sociais. Opladen: Leske + Budrich, 82-IIo. 1995b.

FUCHS, M., LUEDTKE, J. Gangues juvenis e comportamentos relacionados a gangues. Erscheint in: SCHEITHAUER, H., HAYER, T., NIEBANK, K., Eds., Problemverhalten und Gewalt im Jugendalter. Erscheinungsformen, Entstehungsbedingungen und Möglichkeiten der Prävention. Stuttgart (in Press). 2008.

FURLONG, M. J., CHUNG, A. Quem são as vítimas de violência escolar? Uma comparação entre estudantes não vítimas e multivítimas, em Educação e tratamento de crianças, $18(3)$, p.82-298. 2003.

GARCIA, I. S. e TOLFO, S. R. Assédio moral no trabalho: uma responsabilidade coletiva. sicologia e Sociedade, 23(II), p.190-192. 2011.

GIL, Antônio Carlos. Métodos e técnicas de pesquisa social. 5. ed. São Paulo: Atlas, 2008.

KILPATRICK-DEMARAY, M., e Kerres-Malecki, C. Percepções da frequência e importância do apoio social de estudantes classificados como vítimas, agressores e agressores / agressores em uma escola urbana. School Psychology Review, 32(3), p.47i-489. 2003.

LEFF, S. S., Power, T. J., Costigan, T. E., e Manz, P. H. Avaliando o clima do playground e da lanchonete: implicações para a programação de prevenção ao bullying. Revisão de Psicologia Escolar, 32(3), p.418-430. 2003.

LIMBER, S.P. e Small, M.A. Leis e políticas estaduais para combater o bullying nas escolas. School Psychology Review, 32 (3), p.445-455. 2003.

LEYMANN, Heinz. Bullying: a perseguição ao trabalho. Paris: Seuil, I996 DENIS, Paul. Emoção e satisfação: o deux formata a pulsão. Paris: PUF, 1997. 
MATTOS E SILVA, R.V. Reencontro de filologia e linguística nos estudos diacrônicos. Linguagem, I: p.74-82. 1983.

MANSEL, J. educação familiar e experiências de violência. Antecedentes e consequências da vitimização, em Zeitschrift für Familienforschung, I3 (3), p.27-51. 200 I.

MEIER, U., TILLMANN, K.-J. Violência na escola - importados ou autoproduzidos? na prática da psicologia infantil e da psiquiatria infantil, 49, 36-52.

Moraes, Rita. A lei do mais forte. ISTO É, São Paulo, n.1542, p. 84-89, 2010.

NCUBE, N. O sistema familiar como determinante socioecológico do bullying entre adolescentes do ensino médio urbano em Gweru, Zimbábue: implicações para a intervenção. Ciência Social asiática, p.91 (7). 2013.

OLWEUS, D. Bullying na escola: o que sabemos e o que podemos fazer. Oxford, Reino Unido: falta de recursos. 1993.

RODKIN, P.C., e HODGES, E.V. Valentões e vítimas na ecologia de pares: quatro perguntas para psicólogos e profissionais da escola. School Psychology Review, 32 (3), p.384400. 2013 .

SMITH, P.K., (Ed.). Violência nas escolas: a resposta na Europa. Londres, Nova York, Routledge. 20I8.UNESCO. Violência escolar e bullying: Global Status Report. Paris: UNESCO, 2017. 